\title{
Characteristics of COPD patients according to GOLD classification and clinical phenotypes in the Russian Federation: the SUPPORT trial
}

This article was published in the following Dove Press journal:

International Journal of COPD

3 November 2017

Number of times this article has been viewed

\author{
Vladimir Arkhipov' \\ Daria Arkhipova ${ }^{2}$ \\ Marc Miravitlles ${ }^{3}$ \\ Andrey Lazarev ${ }^{4}$ \\ Ekaterina Stukalina ${ }^{5}$ \\ 'Clinical Pharmacology and Therapy \\ Department, Russian Medical \\ Academy of Postgraduate Education, \\ Moscow, Russian Federation; ${ }^{2}$ Clinical \\ Pharmacology and Propaedeutic \\ Internal Diseases Department, First \\ Moscow State Medical University, \\ Moscow, Russian Federation; \\ ${ }^{3}$ Pneumology Department, Hospital \\ Universitari Vall d'Hebron, Ciber \\ de Enfermedades Respiratorias \\ (CIBERES), Barcelona, Spain; \\ ${ }^{4}$ AstraZeneca Pharmaceuticals, \\ Moscow, Russian Federation; \\ ${ }^{5}$ AstraZeneca LP, Gaithersburg, \\ MD, USA
}

Background: The high prevalence of COPD in the Russian Federation has been demonstrated in several epidemiological studies. However, there are still no data on the clinical characteristics of these patients according to Global Initiative for Chronic Obstructive Lung Disease (GOLD) groups and phenotypes, which could provide additional understanding of the burden of COPD, routine clinical practice, and ways to improve the treatment of patients with COPD in Russia. Patients and methods: SUPPORT was an observational multicenter study designed to obtain data about the distribution of patients with previously diagnosed COPD according to the severity of bronchial obstruction, symptom severity, risk of exacerbation, COPD phenotypes, and treatment of COPD. We included patients with a previous diagnosis of COPD who visited one of 33 primary-care centers for any reason in 23 cities in Russia.

Results: Among the 1,505 patients with a previous diagnosis of COPD who attended the primary-care centers and were screened for the study, 1,111 had a spirometry-confirmed diagnosis and were included in the analysis. Up to $53 \%$ of the patients had severe or very severe COPD (GOLD stages III-IV), and $74.3 \%$ belonged to the GOLD D group. The majority of patients were frequent exacerbators (exacerbators with chronic bronchitis [37.3\%], exacerbators without chronic bronchitis [14\%]), while $35.8 \%$ were nonexacerbators and $12.9 \%$ had asthma-COPD overlap. Among the GOLD D group patients, $>20 \%$ were treated with only short-acting bronchodilators.

Conclusion: COPD is still misdiagnosed in primary care in Russia. COPD patients in primary care are usually GOLD D with frequent exacerbations and are often treated with only shortacting bronchodilators.

Keywords: COPD, spirometry, observational study, Russian Federation, phenotypes

\section{Introduction}

COPD is a leading cause of morbidity and mortality, and accounted for 3 million deaths worldwide in 2012. ${ }^{1}$ The estimated prevalence of COPD varies considerably among countries, depending on the population studied and the study methodology..$^{2-6}$ An epidemiological study conducted in 12 regions of the Russian Federation estimated a COPD prevalence of $15.3 \%,{ }^{7}$ while other studies have reported prevalence of between $6.8 \%$ and $21 \% .{ }^{8,9}$ Recent studies have also suggested that the prevalence could be even higher. ${ }^{710}$ The smoking rate in the Russian Federation is also high, with $61 \%$ of men and $22.1 \%$ of women being active smokers. ${ }^{11}$

Previous studies have provided data on the prevalence and demographics of COPD in the Russian Federation, ${ }^{7,9,10}$ but there is still a lack of information related to disease severity, clinical phenotypes, and treatment approaches used in routine
Correspondence: Vladimir Arkhipov Clinical Pharmacology and Therapy Department, Russian Medical Academy of Postgraduate Education, Moscow, Russian Federation

Tel +7 4954428142

Email arkhipov@gmx.us 
clinical practice. However, the results of the POPE study showed that the majority of COPD patients in Central and Eastern Europe belong to the Global Initiative for Chronic Obstructive Lung Disease (GOLD) D group and have frequent exacerbations. ${ }^{12}$ Numerous studies have shown that the treatment of COPD patients in Europe does not necessarily follow the guidelines, ${ }^{13-15}$ but at present there are no data available regarding pharmacological treatment in primary care in the Russian Federation. Therefore, the objective of this study was to describe the characteristics and treatment of COPD patients in primary care in the Russian Federation.

\section{Patients and methods}

\section{Study design and patients}

SUPPORT was a cross-sectional, observational study conducted in 33 primary-care centers in 23 cities in the Russian Federation from November 2014 to May 2015 (NCT02248909). The two main objectives of the study were 1) to describe the characteristics of patients with a previous diagnosis of COPD and the adequacy of treatment, according to international recommendations and clinical phenotypes, and 2) to assess the use of spirometry as a screening tool in individuals with risk factors for COPD. The present article addresses the results of the first objective.

Participants were enrolled in the study when they visited the primary-care centers, irrespective of the reason for their appointment with the doctor. Inclusion criteria were patients $\geq 18$ years old with a previous diagnosis of COPD, considered by the investigator to be able to complete the questionnaires and undergo spirometry, and postbronchodilator forced expiratory volume in 1 second $\left(\mathrm{FEV}_{1}\right)$ /forced vital capacity $(\mathrm{FVC})<0.7$. Exclusion criteria were previous lung or bronchial surgery, presence of other respiratory diseases that interfere in the clinical assessment of COPD, and patients participating in any other interventional clinical trial.

The study was approved by the Independent Interdisciplinary Ethics Committee on Ethical Review for Clinical Studies, Moscow, Russia. The study followed all applicable regulatory and administrative requirements of routine medical practice in the Russian Federation. All the patients studied provided written informed consent to participate in the study.

\section{Study assessments}

Demographic data and clinical characteristics of patients were collected during the primary-care visit, including information regarding COPD treatment, previous exacerbations, and exposure to toxic substances (smoking history, occupational exposure, and home biomass exposure). The degree of baseline dyspnea was measured using the modified Medical Research Council (mMRC) scale. ${ }^{16}$ Symptoms were gauged with the COPD assessment test (CAT), which is a specific questionnaire that measures the impact of the disease in patients with eight questions assessing cough, expectoration, dyspnea, chest tightness, confidence, limitation of daily activities, quality of sleep, and energy levels. The score ranges from 0 to 40, with 40 being the worst possible health state and 0 the best. ${ }^{17}$ Health-related quality of life was assessed using the St George's Respiratory Questionnaire (SGRQ), which is a standardized self-administered respiratory disease-specific questionnaire divided into three subscales: symptoms (eight items), activity (16 items), and impact (26 items). For each subscale and the overall questionnaire, scores range from 0 (no impairment) to 100 (maximum impairment). The minimal important difference for the SGRQ has been established as 4 points. $^{18}$

According to American Thoracic Society/European Respiratory Society standards, ${ }^{19}$ spirometry with a bronchodilator test was performed during the assessment visit. Severity was classified based on the GOLD 2014 recommendations: GOLD 1, mild (FEV $1280 \%$ predicted); GOLD 2, moderate $\left(\mathrm{FEV}_{1} \geq 50 \%\right.$ and $<80 \%$ predicted); GOLD 3, severe ( $\mathrm{FEV}_{1} \geq 30 \%$ and $<50 \%$ predicted); and GOLD 4 , very severe $\left(\mathrm{FEV}_{1}<30 \%\right.$ predicted $){ }^{20}$

Patients were stratified into four groups following the GOLD 2014 group classification based on COPD symptoms (more symptoms, mMRC-scale score $\geq 2$, and/or CAT score $\geq 10$ ), spirometry classification, and the number of exacerbations (high risk, two or more exacerbations the previous year or one hospitalization): A (low risk, fewer symptoms), B (low risk, more symptoms), C (high risk, fewer symptoms), or D (high risk, more symptoms). Additionally, patients in groups $\mathrm{C}$ and $\mathrm{D}$ were stratified into three subgroups as $\mathrm{C}_{1}, \mathrm{C}_{2}$, and $\mathrm{C}_{3}$, and $\mathrm{D}_{1}, \mathrm{D}_{2}$, and $\mathrm{D}_{3}$ based on the specific risk factor used to determine the group assignment: $\mathrm{C}_{1}$ or $\mathrm{D}_{1}\left(\mathrm{FEV}_{1}<50 \%\right), \mathrm{C}_{2}$ or $\mathrm{D}_{2}$ (two or more exacerbations or one hospitalization), and $\mathrm{C}_{3}$ or $\mathrm{D}_{3}$ (both $\mathrm{FEV}_{1}<50 \%$ and two or more exacerbations or one hospitalization within the last year). ${ }^{20}$ Exacerbations were defined based on the GOLD 2014 recommendations as an acute event characterized by a worsening of the patient's respiratory symptoms that is beyond normal day-to-day variations and leads to a change in medication.

As for clinical phenotypes, patients were classified according to the clinical phenotypes described in previous studies in Eastern and Central Europe ${ }^{12}$ and Spain: ${ }^{21}$ patients with two or more exacerbations during the previous year were 
classified as frequent exacerbators with or without chronic bronchitis, and those with a previous diagnosis of asthma were identified as having asthma-COPD overlap (ACO). The remaining COPD patients were classified as nonexacerbators. Chronic bronchitis was defined as cough and sputum for at least 3 months during 2 consecutive years. ${ }^{20}$

\section{Statistical analysis}

Absolute frequencies and percentages were used to describe the qualitative variables. With regard to the quantitative variables, measurements of central tendency (mean, median), measurements of position (quartiles), and dispersion (SD or IQR) were used. Patient characteristics were compared using Student's $t$-test (Mann-Whitney $U$ test if normality was not assumed). The $\chi^{2}$ test (Fisher's test for frequencies $<5$ ) was employed for the comparison of categorical variables. Linear correlation was analyzed by the Pearson test. Analysis was performed for the full-analysis set and subgroup data sets. Statistical significance was set at $\alpha=0.05$.

\section{Results}

During the study period, a total of 86,300 visits were recorded in the study sites, of which 3,515 (4.1\%) individuals with a previous diagnosis of COPD were identified and 1,505 signed the informed consent ( $42.8 \%$ of those identified) to participate in the study. Spirometry testing demonstrated that 269 patients did not fulfill the spirometric criterion for COPD, and they were not included in the final analysis, representing a rate of overdiagnosis of $19.5 \%$ (269 of the 1,381 postbronchodilator spirometry results available) (Figure 1). Among

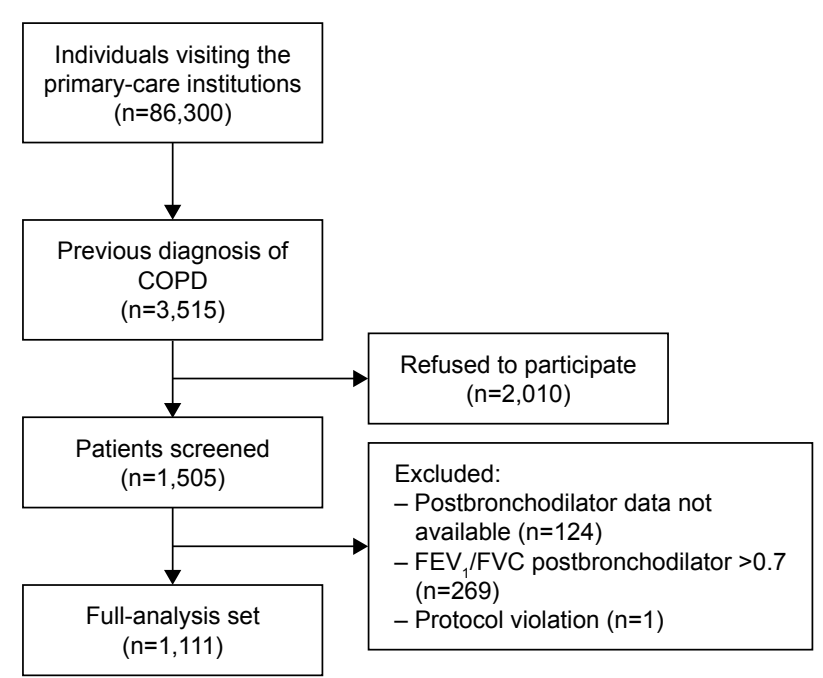

Figure I Patient primary-care institutions.

Abbreviations: $\mathrm{FEV}_{1}$, forced expiratory volume in I second; FVC, forced vital capacity. the 1,111 patients included, $85.2 \%$ were men with a mean age of 64.1 (SD 9.1) years. Almost half of the patients were active smokers, and $44.4 \%$ had had occupational exposure associated with risk for respiratory disease. The characteristics of the patients are described in Table 1.

\section{Distribution and characteristics of patients according to GOLD classification}

According to the GOLD severity stages, the majority of patients corresponded to stages 2 and 3 (Table 1). Only 1.4\% and $1.8 \%$ of patients had a CAT score $<10$ and were classified as GOLD $A$ and $C$, respectively, while $22.4 \%$ and $74.4 \%$ were GOLD B and D, respectively (Table 2, Figure 2). Among the patients in the GOLD D group, $22.8 \%$ were $\mathrm{D}_{1}, 30.1 \% \mathrm{D}_{2}$, and $47 \% \mathrm{D}_{3}\left(17 \%\right.$ of the overall cohort for $\mathrm{D}_{1}, 22.5 \%$ for $\mathrm{D}_{2}$, and $34.9 \%$ for $\mathrm{D}_{3}$; Figure 2). Group $\mathrm{C}$ was stratified but not analyzed, due to the small number of patients in this group.

There were no differences regarding age for the four GOLD groups. Patients in the GOLD D group had

Table I Patient characteristics of the whole sample $(n=I, I$ I I)

\begin{tabular}{ll}
\hline Age, years & $64.1(9.1)$ \\
Sex, male, n (\%) & $946(85.2)$ \\
Smokers, n (\%) & $542(48.8)$ \\
Never smoked, n (\%) & $50(4.5)$ \\
Ex-smoker, n (\%) & $519(46.7)$ \\
Smoking history, pack-years & $39.9(20.6)$ \\
Occupational exposure, n (\%) & $493(44.4)$ \\
BMI (kg/m²) & $26.1(5.3)$ \\
Time after symptom onset, years & $12.3(8.2)$ \\
FEV, L & $1.44(0.7)$ \\
FEV, \% & $48.9(16.5)$ \\
GOLD I, n (\%) & $42(3.8)$ \\
GOLD 2, n (\%) & $480(43.2)$ \\
GOLD 3, n (\%) & $457(4 I .1)$ \\
GOLD 4, n (\%) & $132(11.9)$ \\
CAT score & $22.3(7.6)$ \\
SGRQ score & $59.1(18.4)$ \\
Comorbidity, n (\%) &
\end{tabular}

Notes: Data expressed as mean (SD), unless specified otherwise. GOLD I, mild ( $F E V_{1} \geq 80 \%$ predicted); GOLD 2, moderate ( $\mathrm{FEV}_{1} \geq 50 \%$ and $<80 \%$ predicted); GOLD 3 , severe ( $F E V_{1} \geq 30 \%$ and $<50 \%$ predicted); and GOLD 4 , very severe (FEV, $30 \%$ predicted).

Abbreviations: BMI, body mass index; CAT, COPD assessment test; $\mathrm{FEV}_{1}$, forced expiratory volume in I second; GOLD, Global Initiative for Chronic Obstructive Lung Disease; SGRQ, St George's Respiratory Questionnaire. 
Table 2 Patient characteristics according to GOLD 2014 groups

\begin{tabular}{|c|c|c|c|c|c|c|c|}
\hline Characteristics & $\begin{array}{l}\text { GOLD A } \\
(n=16)\end{array}$ & $\begin{array}{l}\text { GOLD B } \\
(n=249)\end{array}$ & $\begin{array}{l}\text { GOLD C } \\
(n=20)\end{array}$ & $\begin{array}{l}\text { GOLD D } \\
(n=826)\end{array}$ & $\begin{array}{l}\text { GOLD D, } \\
(n=189)\end{array}$ & $\begin{array}{l}\text { GOLD } D_{2} \\
(n=249)\end{array}$ & $\begin{array}{l}\text { GOLD } D_{3} \\
(n=388)\end{array}$ \\
\hline Age, years & $61.8(9.7)$ & $64.2(9)$ & $63.8(11)$ & $63.5(9.1)$ & $65.1(9.2)$ & $64.7(9.6)$ & $63.1(8.6)$ \\
\hline Sex (men), n (\%) & $15(93.8)$ & $207(83.1)$ & $16(80)$ & $708(85.7)$ & $168(88.9)$ & $197(79.1)$ & $343(88.4)$ \\
\hline Active smokers, n (\%) & $6(37.5)$ & $129(51.8)$ & $5(25)$ & $403(48.8)$ & I0I (53.4) & $107(43)$ & $195(50.3)$ \\
\hline Occupational exposure, n (\%) & $10(62.5)$ & $92(37)$ & $4(20)$ & $387(46.8)$ & $84(44.4)$ & $119(47.8)$ & $184(47.4)$ \\
\hline $\mathrm{BMI}, \mathrm{kg} / \mathrm{m}^{2}$ & $28.5(4.3)$ & $27.1(5)$ & $27.3(5.5)$ & $25.8(5.3)$ & $25.3(4.9)$ & $26.5(5.2)$ & $25.4(5.5)$ \\
\hline Time after symptom onset, years & $8(6.2)$ & $11.3(7)$ & $12.2(8.4)$ & $12.6(8.5)$ & $12(8.4)$ & $12.9(9.3)$ & $12.7(8.1)$ \\
\hline Time after diagnosis, years & $6.2(5.6)$ & $5.3(4.2)$ & $5.5(3.7)$ & $6.4(5.1)$ & $5.7(4.8)$ & $6.3(5.1)$ & $6.7(5.3)$ \\
\hline Postbronchodilator FEV (\%) & $63.6(9.7)$ & $63.6(10.5)$ & $52.4(18.4)$ & $44.3(17.5)$ & $38(8.2)$ & $62.7(10.2)$ & $35.2(8.6)$ \\
\hline CAT score & $6.9(2.1)$ & $19.9(6.4)$ & $7.6(1.5)$ & $22.8(7)$ & $19.9(6.7)$ & $22.1(7.3)$ & $24.7(6.9)$ \\
\hline SGRQ score & $30.1(15)$ & $49.8(18)$ & $34.1(19.9)$ & $62.9(1.8)$ & $59.5(17.4)$ & $61(16.5)$ & $66(15.6)$ \\
\hline \multicolumn{8}{|l|}{ Comorbidity, n (\%) } \\
\hline Any disease & $12(75)$ & 189 (75.9) & $12(60)$ & $620(75.1)$ & I $33(70.4)$ & I 88 (75.5) & $299(77.1)$ \\
\hline Chronic heart failure & I (6.2) & $39(16)$ & $4(20)$ & $154(18.6)$ & No data & No data & No data \\
\hline Diabetes mellitus & 0 & $19(7.6)$ & $\mathrm{I}(5)$ & $64(7.7)$ & No data & No data & No data \\
\hline Asthma & $\mathrm{I}(6.3)$ & $33(13.2)$ & $3(15)$ & $106(12.8)$ & $29(15.3)$ & $28(11.2)$ & $49(12.6)$ \\
\hline Cardiovascular diseases & $8(50)$ & $147(59)$ & II (55) & $544(65.9)$ & $107(56.6)$ & $180(72.2)$ & $257(66.2)$ \\
\hline Exacerbation requiring hospitalization, $\mathrm{n}(\%)$ & NA & NA & $6(30)$ & $533(64.5)$ & NA & $196(78.7)$ & $337(86.9)$ \\
\hline Emergency visits due to COPD, $\mathrm{n}(\%)$ & 0 & $34(13.7)$ & $6(30)$ & $353(42.7)$ & $32(16.9)$ & $108(43.4)$ & $213(54.9)$ \\
\hline
\end{tabular}

Notes: Data expressed as means (SD), unless specified otherwise. GOLD A (low risk, fewer symptoms), GOLD B (low risk, more symptoms), GOLD C (high risk, fewer symptoms), or GOLD D (high risk, more symptoms). Patients in groups $C$ and $D$ were stratified into three subgroups as $C_{1}, C_{2}$, and $C_{3}$, and $D_{1}, D_{2}$, and $D_{3}$ based on the specific risk factor used to determine the group assignment: $C_{1}$ or $D_{1}\left(F E V_{1}<50 \%\right), C_{2}$ or $D_{2}$ (two or more exacerbations or one hospitalization), and $C_{3}$ or $D_{3}$ (both $F E V_{1}$ $<50 \%$ and two or more exacerbations or one hospitalization within the last year).

Abbreviations: BMI, body mass index; CAT, COPD assessment test; FEV , forced expiratory volume in I second; GOLD, Global Initiative for Chronic Obstructive Lung Disease; SGRQ, St George's Respiratory Questionnaire; NA, not applicable.

lower body mass index compared with those in GOLD A $\left(25.8 \mathrm{~kg} / \mathrm{m}^{2}\right.$ versus $\left.28.5 \mathrm{~kg} / \mathrm{m}^{2}\right)$. Patients in the GOLD B and $\mathrm{D}$ groups were more frequently active smokers $(51.8 \%$ and $48.8 \%$, respectively) compared with the less symptomatic patients (37.5\% in GOLD $A$ and $25 \%$ in GOLD C). They also had worse quality of life measured by the SGRQ compared with GOLD A and C patients. Among GOLD D patients, those in GOLD $\mathrm{D}_{3}$ had the worst quality of life. Patients in GOLD D - and among these, GOLD $D_{3}$ - had also more frequently visited the emergency department and had more hospitalizations (Table 2).

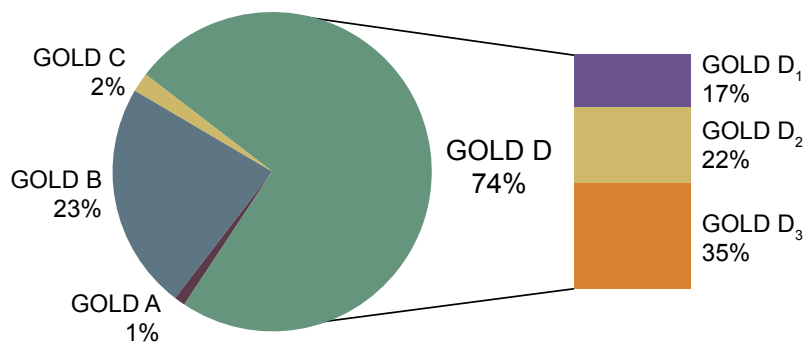

Figure 2 Distribution of patients by GOLD 2013 group.

Notes: GOLD A (low risk, fewer symptoms), GOLD B (low risk, more symptoms), GOLD C (high risk, fewer symptoms), or GOLD D (high risk, more symptoms). Patients in groups $C$ and $D$ were stratified into three subgroups as $C_{1}, C_{2}$, and $C_{3}$, and $D_{1}, D_{2}$, and $D_{3}$ based on the specific risk factor used to determine the group assignment: $\mathrm{C}_{1}$ or $\mathrm{D}_{1}(\mathrm{FEV},<50 \%), \mathrm{C}_{2}$ or $\mathrm{D}_{2}$ (two or more exacerbations or one hospitalization), and $\mathrm{C}_{3}$ or $\mathrm{D}_{3}$ (both $\mathrm{FEV},<50 \%$ and two or more exacerbations or one hospitalization within the last year).

Abbreviation: GOLD, Global Initiative for Chronic Obstructive Lung Disease.

\section{Distribution and characteristics of clinical COPD phenotypes}

In total, $51.3 \%$ of patients were frequent exacerbators, with $37.3 \%$ of these having chronic bronchitis. Up to $12.9 \%$ had a previous diagnosis of asthma and were diagnosed with ACO (Figure 3, Table 3). Compared with the others, ACO patients
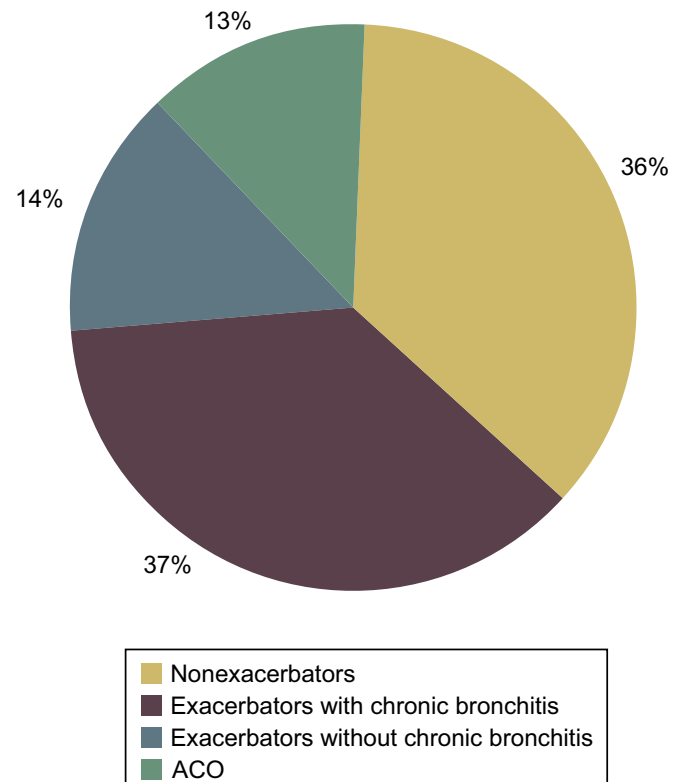

Figure 3 Distribution of patients by clinical phenotype. Abbreviation: ACO, asthma-COPD overlap. 
Table 3 Patient characteristics according to clinical phenotypes

\begin{tabular}{|c|c|c|c|c|}
\hline Characteristics & $\begin{array}{l}\text { Nonexacerbators } \\
(n=398)\end{array}$ & $\begin{array}{l}\text { ACO } \\
(n=143)\end{array}$ & $\begin{array}{l}\text { Exacerbators } \\
\text { with } C B(n=4 \mid 5)\end{array}$ & $\begin{array}{l}\text { Exacerbators } \\
\text { without } C B(n=\mid 55)\end{array}$ \\
\hline Age, years & $64.7(8.9)$ & $60.5(10.7)$ & $64.6(8.5)$ & $64.4(9.1)$ \\
\hline Sex (men), n (\%) & $347(87.2)$ & $113(79)$ & $356(85.8)$ & $130(83.9)$ \\
\hline Smokers, n (\%) & $219(55)$ & $50(35)$ & $213(51.3)$ & $60(38.7)$ \\
\hline Smoking history, pack-years & $40.7(20.1)$ & $35.1(22.8)$ & $41.7(20.7)$ & $38.1(18.4)$ \\
\hline $\mathrm{BMI}, \mathrm{kg} / \mathrm{m}^{2}$ & $26.5(5.1)$ & $26.9(5.8)$ & $25.8(5.3)$ & $25.4(5)$ \\
\hline Mean age at symptom onset, years & $53.4(10.4)$ & $48.5(12.1)$ & $50.6(11.9)$ & $53.9(10.7)$ \\
\hline $\mathrm{FEV}, \%$ & $52.9(16.2)$ & $48.4(15.6)$ & $47.1(15.9)$ & $44.3(17.6)$ \\
\hline GOLD I, n (\%) & $19(4.8)$ & $4(2.8)$ & $12(2.9)$ & $7(4.5)$ \\
\hline GOLD 2, n (\%) & $211(53)$ & $60(42)$ & $159(38.3)$ & $50(32.3)$ \\
\hline GOLD 3, n (\%) & $138(34.7)$ & $64(44.7)$ & $192(46.3)$ & $63(40.6)$ \\
\hline GOLD 4, n (\%) & $30(7.5)$ & $15(10.5)$ & $52(12.8)$ & $35(22.6)$ \\
\hline CAT score & $19.7(7)$ & $21(7.5)$ & $24.7(7.5)$ & $23.4(7)$ \\
\hline SGRQ total score & $52.3(18.9)$ & $58.7(17.3)$ & $65(16.2)$ & $59.4(18.5)$ \\
\hline \multicolumn{5}{|l|}{ Comorbidities, n (\%) } \\
\hline Any disease & $295(74.1)$ & $73(5 \mathrm{I})$ & $357(86)$ & $108(69.7)$ \\
\hline Any cardiovascular & $247(62.1)$ & $55(38.5)$ & $310(74.7)$ & $98(63.2)$ \\
\hline Chronic heart failure & $68(19.1)$ & $16(11.2)$ & $93(22.41)$ & $21(13.6)$ \\
\hline Diabetes mellitus & $27(6.8)$ & $6(4.2)$ & $40(9.6)$ & II (7.I) \\
\hline \multicolumn{5}{|c|}{ Exacerbations during the previous year, $\mathrm{n}(\%)$} \\
\hline One exacerbation & $40(10)$ & $5(3.5)$ & $40(9.6)$ & $14(9)$ \\
\hline Two or more exacerbations & 0 & $10(7)$ & $90(21.7)$ & $20(12.9)$ \\
\hline Hospitalizations & 0 & $79(55.2)$ & $325(78.3)$ & $135(87.1)$ \\
\hline
\end{tabular}

Notes: Data expressed as means (SD), unless specified otherwise. GOLD I, mild ( $\mathrm{FEV}_{1} \geq 80 \%$ predicted); GOLD 2, moderate (FEV $1 \geq 50 \%$ and $<80 \%$ predicted); GOLD 3 , severe ( $\mathrm{FEV}, \geq 30 \%$ and $<50 \%$ predicted); and GOLD 4 , very severe ( $\mathrm{FEV}, 30 \%$ predicted).

Abbreviations: ACO, asthma-COPD overlap; BMI, body mass index; CAT, COPD assessment test; $C B$, chronic bronchitis; FEV , forced expiratory volume in I second; GOLD, Global Initiative for Chronic Obstructive Lung Disease; SGRQ, St George's Respiratory Questionnaire.

tended more frequently to be female and less frequently active smokers. Patients in the ACO and exacerbator phenotypes were more frequently severe or very severe. On the contrary, nonexacerbators tended to have milder COPD (Table 3). Nonexacerbators had better quality of life measured by the SGRQ and lower (better) CAT score compared with exacerbators, either with or without chronic bronchitis (Table 3 ).

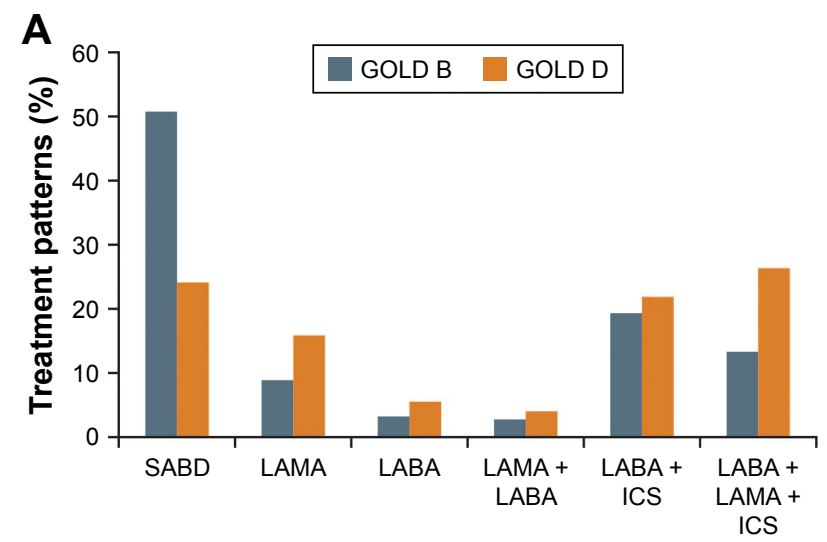

\section{Treatment patterns based on GOLD groups}

Treatment with short-acting bronchodilators (SABDs) was frequent in GOLD B and D patients (51\% and $24.2 \%$, respectively) and even in GOLD $\mathrm{D}_{3}$ patients $(19.1 \%)$ (Figure 4A), while $12.8 \%$ and $3.2 \%$ of GOLD B patients were treated with a long-acting bronchodilator (LABD) in

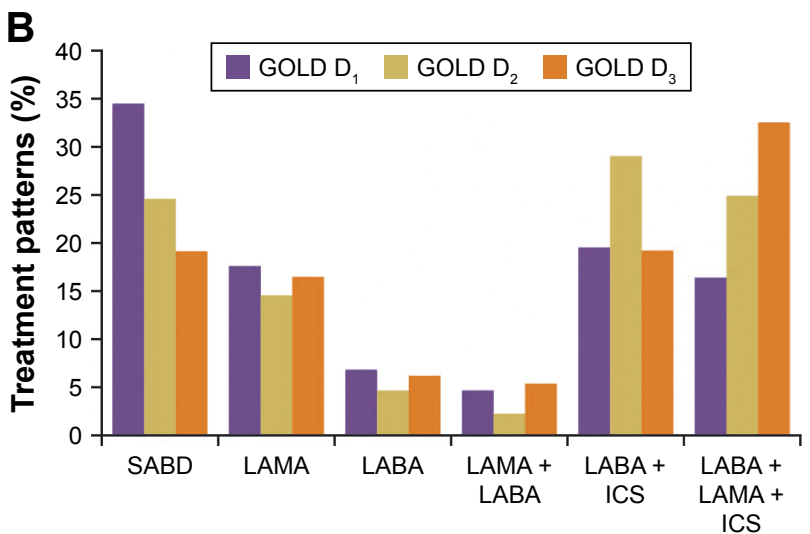

Figure 4 (A) Treatment patterns by GOLD 2014 B and D; (B) treatment patterns by GOLD D subgroups.

Notes: GOLD B (low risk, more symptoms), GOLD D (high risk, more symptoms). Patients in group $D$ were stratified into three subgroups as $D_{1}$, $D_{2}$, and $D_{3}$ based on the specific risk factor used to determine the group assignment: $\mathrm{D}_{1}(\mathrm{FEV},<50 \%), \mathrm{D}_{2}$ (two or more exacerbations or one hospitalization), and $\mathrm{D}_{3}$ (both $\mathrm{FEV},<50 \%$ and two or more exacerbations or one hospitalization within the last year).

Abbreviations: SABD, short-acting bronchodilator; LAMA, long-acting muscarinic antagonist; LABA, long-acting $\beta_{2}$-agonist; ICS, inhaled corticosteroid; GOLD, Global Initiative for Chronic Obstructive Lung Disease. 
monotherapy or a combination of a long-acting $\beta$-agonist (LABA) and long-acting muscarinic antagonist (LAMA), respectively; $33.3 \%$ of GOLD B patients and $48.7 \%$ of GOLD $\mathrm{D}$ patients received inhaled corticosteroids (ICSs). Moreover, in group D, $54.5 \%$ of patients treated with a regime including ICS were on triple therapy (Figure 4B), which was more frequently prescribed in the GOLD $\mathrm{D}_{3}$ subgroup of patients ( $63 \%$ of those with an ICS regimen).

\section{Discussion}

The results of this study show that COPD is still frequently misdiagnosed in the Russian Federation. The majority of our patients had a high number of symptoms (GOLD B and more frequently GOLD D), and half were frequent exacerbators. A large number of patients were treated with SABDs, including GOLD D patients with poor lung function and frequent exacerbations.

The frequency of COPD in our study population of patients attending primary-care clinics was $4.1 \%$, being somewhat low compared with previous epidemiological studies conducted in the Russian Federation. A recent study estimated a prevalence of $6.8 \%$ in individuals $30-70$ years of age,${ }^{9}$ increasing up to $15.3 \%$ in symptomatic individuals $>30$ years old. ${ }^{7}$ Although these differences could be due to the heterogeneity of the populations included and the methodology used, it may also suggest the underdiagnosis of the disease in this primary-care setting. Conversely, $19.5 \%$ of those with a previous diagnosis of COPD had not undergone obstructive spirometry, and this rate of overdiagnosis is similar to that observed in other epidemiological studies. ${ }^{22,23}$ Wider implementation of spirometry as a screening method for COPD in clinical practice may help to prevent both the underdiagnosis and the overdiagnosis of COPD observed in this study. In the case of underdiagnosis, broader use of screening for patients with known COPD risk factors, targeting diagnosis at an earlier stage of disease, could be beneficial.

The majority of patients corresponded to GOLD stages 2 and 3. Moreover, most of these patients had a high symptom burden and were classified as GOLD D and B. In the POPE study, conducted in Central and Eastern Europe, the authors reported a similar distribution, with $57 \%$ of patients being GOLD D and $30.6 \%$ GOLD B, ${ }^{12}$ while in a recent study in Spain, Miravitlles et al also found GOLD D and B to be the most prevalent groups (64.2\% and $19.1 \%$, respectively). ${ }^{24}$ However, this distribution of patients substantially differs from that in other European countries, ${ }^{25}$ where patients in group D represented only $43.2 \%$, while groups A and B were more frequent compared to the Russian Federation. The majority of GOLD D patients were classified as such based on exacerbation history alone or in combination with a low $\mathrm{FEV}_{1}$, similar to the results reported by Jones et $\mathrm{al}^{26}$ and in contrast to data from the ECLIPSE study, in which only $9 \%$ of patients were classified as GOLD D by exacerbation history alone. ${ }^{27}$

Up to $12.9 \%$ of patients studied had a previous diagnosis of asthma and were diagnosed with ACO, which is similar to the estimated prevalence of ACO in Spain and the USA. ${ }^{28,29}$ More than $55 \%$ of ACO patients were hospitalized for disease exacerbation within the last year, which was less frequent than for exacerbators with and without chronic bronchitis (78.3\% and $87.1 \%$ respectively). Compared with frequent exacerbators, ACO patients had fewer symptoms and better quality of life. The low number of exacerbations and relatively higher quality of life in patients with ACO may be associated with ICS treatment, which was received by $60 \%$ of these patients.

In total, half of the patients were frequent exacerbators and only $36 \%$ were nonexacerbators. In contrast to these data, other authors and data from Eastern Europe have described two-thirds of patients to be nonexacerbators. ${ }^{12,30,31}$ Nevertheless, patients with chronic bronchitis are common among exacerbators, which is consistent with previous studies. ${ }^{30,31}$ In accordance with previous reports, exacerbators were more severe and had more symptoms, worse quality of life, and more hospitalizations compared with other phenotypes. ${ }^{27,32,33}$ In addition, exacerbators with chronic bronchitis often had more comorbidities compared with exacerbators without chronic bronchitis. ${ }^{30}$

Treatment varied significantly among the different GOLD groups, and we observed low adherence to treatment recommendations. Up to $30 \%$ of GOLD D patients were treated with an SABD as monotherapy, being a frequent treatment pattern for all COPD patients. Similar results have been observed in other countries, where studies have shown that less than half of the COPD patients received maintenance treatment. ${ }^{13-15}$ On the other hand, treatment with LABD or a combination of $L A B D$ was relatively rare $(24 \%$ for all GOLD B and D patients), similar to data from other European countries. ${ }^{13,15}$ Less than half of GOLD D patients received ICS, with approximately a 1:1 split between dual and triple therapies.

While our study did not assess the underlying reasons for choice of therapy, recent studies in the USA have highlighted a number of potential barriers that may prevent physicians from adhering to GOLD recommendations. These include unfamiliarity with GOLD recommendations, difficulties in 
assessing response to therapy, and failure to recognize subtle improvements with LABD therapy. ${ }^{34,35}$ Lack of familiarity with GOLD recommendations by physicians may have led to patients receiving incorrect GOLD group classifications, and subsequently not being prescribed the most appropriate therapies. This may be partly responsible for the low adherence to treatment recommendations observed. Insufficient maintenance therapy may have contributed to the high burden of symptoms seen in this study cohort, leading to a greaterthan-expected proportion of patients being classified as GOLD B or GOLD D. Reimbursement policies and willingness of patients to pay for advanced treatments may also have been a contributing factor to failure to receive appropriate therapy and subsequently poor control of symptoms.

Further studies are warranted to identify accurately factors leading to the high frequency of exacerbators in the Russian population. One of the most likely causes is a lack of appropriate treatment to reduce the risk of exacerbations. In our study, we noted that treatment among exacerbators with or without chronic bronchitis was limited to SABD in one in five patients.

Our study has some limitations. First, we only included patients with a previous diagnosis of COPD, and thus, the real prevalence of COPD may be underestimated. Moreover, we were not able to provide data of patients in the GOLD A and C groups, due to the small number of individuals in these groups. Stratification of patients and analysis were performed in line with GOLD 2014, which was valid at the time of the study, but further investigation and reassessment in line with GOLD 2017 could be valuable.

In conclusion, the present study provides the largest data set on the distribution of COPD patients by GOLD classifications and clinical phenotypes in the Russian Federation. Further studies are needed to elucidate the distribution of COPD patients fully, and particularly the reasons for the high prevalence of exacerbators, in order to improve the management of COPD in Russia.

\section{Acknowledgments}

The study was funded by AstraZeneca Russia. The authors thank the investigators and patients who participated in this study, and acknowledge Dr Miriam Barrecheguren (Pneumology Department, Hospital Universitari Vall d'Hebron, Barcelona, Spain) for medical writing services that were funded by AstraZeneca Russia. They also acknowledge Kerry Acheson, $\mathrm{PhD}$, of iMed Comms, an Ashfield company, part of UDG Healthcare PLC, for medical writing support that was funded by AstraZeneca Russia.

\section{Disclosure}

MM has received speaker fees from Boehringer Ingelheim, AstraZeneca, Chiesi, GlaxoSmithKline, Menarini, Teva, Grifols, and Novartis, and consulting fees from Boehringer Ingelheim, GlaxoSmithKline, Gebro Pharma, CSL Behring, Cipla, MedImmune, Mereo Biopharma, Teva, Novartis, and Grifols. VA has received speaker fees from AstraZeneca, Boehringer Ingelheim, Takeda, Chiesi, and Zambon, and consulting fees from AstraZeneca. DA has received speaker fees from AstraZeneca. AL and ES are employees of AstraZeneca. The authors report no other conflicts of interest in this work.

\section{References}

1. World Health Organization. The top 10 causes of death. 2017. Available from: http://www.who.int/mediacentre/factsheets/fs310/en. Accessed January 13, 2017.

2. Buist AS, McBurnie MA, Vollmer WM, et al. International variation in the prevalence of COPD (the BOLD study): a population-based prevalence survey. Lancet. 2007;370(9589):741-750.

3. Miravitlles M, Soriano JB, García-Río F, et al. Prevalence of COPD in Spain: impact of undiagnosed COPD on quality of life and daily life activities. Thorax. 2009;64(10):863-868.

4. Csikesz NG, Gartman EJ. New developments in the assessment of COPD: early diagnosis is key. Int J Chron Obstruct Pulmon Dis. 2014;9:277-286.

5. Menezes AM, Perez-Padilla R, Jardim JR, et al. Chronic obstructive pulmonary disease in five Latin American cities (the PLATINO study): a prevalence study. Lancet. 2005;366(9500):1875-1881.

6. Maio S, Baldacci S, Carrozzi L, et al. Respiratory symptoms/diseases prevalence is still increasing: a 25-yr population study. Respir Med. 2016;110:58-65.

7. Chuchalin AG, Khaltaev N, Antonov NS, et al. Chronic respiratory diseases and risk factors in 12 regions of the Russian Federation. Int J Chron Obstruct Pulmon Dis. 2014;9:963-974.

8. Belevskiy A. GARD in Russia. Available from: http://www.who. int/gard/news_events/GARD\%20in\%20Russia.pdf. Accessed January 13, 2017.

9. Andreeva E, Pokhaznikova M, Lebedev A, Moiseeva I, Kutznetsova O, Degryse JM. The prevalence of chronic obstructive pulmonary disease by the Global Lung Initiative equations in north-western Russia. Respiration. 2016;91(1):43-55.

10. Artyukhov IP, Arshukova IL, Dobretsova EA, Dugina TA, Shulmin AV, Demko IV. Epidemiology of chronic obstructive pulmonary disease: a population-based study in Krasnoyarsk region, Russia. Int J Chron Obstruct Pulmon Dis. 2015;10:1781-1786.

11. Global adult tobacco survey (GATS): Russian Federation 2009 - country report. Available from: http://www.who.int/entity/tobacco/surveillance/ en_tfi_gats_russian_countryreport.pdf. Accessed January 13, 2017.

12. Zbozinkova Z, Barczyk A, Tkacova R, et al. POPE study: rationale and methodology of a study to phenotype patients with COPD in Central and Eastern Europe. Int J Chron Obstruct Pulmon Dis. 2016;11:611-622.

13. Price D, West D, Brusselle G, et al. Management of COPD in the UK primary-care setting: an analysis of real-life prescribing patterns. Int $J$ Chron Obstruct Pulmon Dis. 2014;9:889-905.

14. Wurst KE, Shukla A, Muellerova H, Davis KJ. Respiratory pharmacotherapy use inpatients newly diagnosed with chronic obstructive pulmonary disease in a primary care setting in the UK: a retrospective cohort study. COPD. 2014;11(5):521-530.

15. Barrecheguren M, Monteagudo M, Ferrer J, et al. Treatment patterns in COPD patients newly diagnosed in primary care: a population-based study. Respir Med. 2016;111:47-53. 
16. Bestall JC, Paul EA, Garrod R, Garnham R, Jones PW, Wedzicha JA. Usefulness of the Medical Research Council (MRC) dyspnoea scale as a measure of disability in patients with chronic obstructive pulmonary disease. Thorax. 1999;54(7):581-586.

17. Jones PW, Harding G, Berry P, Wiklund I, Chen WH, Leidy NK. Development and first validation of the COPD assessment test. Eur Respir J. 2009;34(3):648-654.

18. Jones PW, Quirk FH, Baveystock CM. The St George's Respiratory Questionnaire. Respir Med. 1991;85(Suppl B):25-31.

19. Miller MR, Hankinson J, Brusasco V, et al. Standardisation of spirometry. Eur Respir J. 2005;26(2):319-338.

20. Global Initiative for Chronic Obstructive Lung Disease. Global Strategy for the Diagnosis, Management, and Prevention of COPD. Bethesda, MD: GOLD; 2014.

21. Miravitlles M, Soler-Cataluña JJ, Calle M, et al. Spanish COPD guidelines (GesEPOC): pharmacological treatment of stable COPD. Arch Bronconeumol. 2012;48(7):247-257.

22. Llordés M, Jaén A, Almagro P, et al. Prevalence, risk factors and diagnosis accuracy of COPD among smokers in primary care. COPD. 2015;12(4):404-412.

23. Fernández-Villar A, López-Campos JL, Represas-Represas C, et al. Factors associated with inadequate diagnosis of COPD: On-Sint cohort analysis. Int J Obstruct Pulmon Dis. 2015;10:961-967.

24. Miravitlles M, Huerta A, Fernández-Villar A, et al. Generic utilities in chronic obstructive pulmonary disease patients stratified according to different staging systems. Health Qual Life Outcomes. 2014;12:120.

25. Casanova C, Marín JM, Martínez-González C, et al. Differential effect of modified medical research council dyspnea, COPD assessment test, and clinical COPD questionnaire for symptoms evaluation within the new GOLD staging and mortality in COPD. Chest. 2015;148(1):159-168.
26. Jones PW, Nadeau G, Small M, Adamek L. Characteristics of a COPD population categorized using the GOLD framework by health status and exacerbations. Respir Med. 2014;108(1):129-135.

27. Agusti A, Edwards LD, Celli B, et al. Characteristics, stability and outcomes of the 2011 GOLD COPD groups in the ECLIPSE cohort. Eur Respir J. 2013;42(3):636-646.

28. Barrecheguren M, Román-Rodríguez M, Miravitlles M. Is a previous diagnosis of asthma a reliable criterion for asthma-COPD overlap syndrome in a patient with COPD? Int J Chron Obstruct Pulmon Dis. 2015;10:1745-1752.

29. Hardin M, Silverman EK, Barr RG, et al. The clinical features of overlap between COPD and asthma. Respir Res. 2011;12:127.

30. Miravitlles M, Barrecheguren M, Roman-Rodriguez M. Frequency and characteristics of different clinical phenotypes of chronic obstructive pulmonary disease. Int J Tuberc Lung Dis. 2015;19(8):992-998.

31. Cosío BG, Soriano JB, López-Campos JL, et al. Distribution and outcomes of a phenotype-based approach to guide COPD management: results from the CHAIN cohort. PLoS One. 2016;11(9):e0160770.

32. Kim V, Han MK, Vance GB, et al. The chronic bronchitic phenotype of COPD: an analysis of the COPD Gedne study. Chest. 2011; 140(3):626-633.

33. Menezes AM, de Oca MM, Perez-Padilla R, et al. Increased risk of exacerbation and hospitalization in subjects with an overlap phenotype: COPD-asthma. Chest. 2014;145(2):297-304.

34. Perez X, Wisnivesky JP, Lurslurchachai L, et al. Barriers to adherence to COPD guidelines among primary care providers. Respir Med. 2012;106(3):374-381.

35. Salinas GD, Williamson JC, Kalhan R, et al. Barriers to adherence to chronic obstructive pulmonary disease guidelines by primary care physicians. Int J Chron Obstruct Pulmon Dis. 2011;6:171-179.
International Journal of COPD

\section{Publish your work in this journal}

The International Journal of COPD is an international, peer-reviewed journal of therapeutics and pharmacology focusing on concise rapid reporting of clinical studies and reviews in COPD. Special focus is given to the pathophysiological processes underlying the disease, intervention programs, patient focused education, and self management protocols.

\section{Dovepress}

This journal is indexed on PubMed Central, MedLine and CAS. The manuscript management system is completely online and includes a very quick and fair peer-review system, which is all easy to use. Visit http://www.dovepress.com/testimonials.php to read real quotes from published authors. 